\title{
Learning and Students' Experiences with Blended Education
}

\author{
Edyta Just ${ }^{1}$ \\ ${ }^{1}$ Associate Professor (Docent), Senior Lecturer, Director of Studies, Director and Coordinator of InterGender- \\ International Consortium for Interdisciplinary Feminist Research Training, Gender Studies, Department of Thematic \\ Studies, Linköping University, Sweden \\ Correspondence: Edyta Just, Tema Genus, Linköping University, 58183 Linköping, Sweden.
}

Received: June 28, 2021

Accepted: August 12, 2021

Online Published: August 17, 2021

doi:10.5430/ijhe.v10n6p213

URL: https://doi.org/10.5430/ijhe.v10n6p213

\begin{abstract}
The article presents the outcomes of the research project supported by Linköping University, Sweden. The research project constitutes a part of an umbrella project called Pedagogiska Utvecklingsmedel för E-lärande 2019 (Pedagogical Development Tools for E-learning 2019). The research project focuses on the International Master's Program "Gender Studies - Intersectionality and Change" offered at the Unit of Gender Studies, Department of Thematic Studies, Faculty of Arts and Sciences, Linköping University, Sweden. The main aims of the research project are to determine which teaching content, teaching methods, learning activities, teacher's role, and students' own strategies matter for learning i.e., for acquiring knowledge and skills/competences in an international blended, face-to-face and online, Master's Program, and to present students' experiences with face-to-face and online education in the Program. The project is based on qualitative, semi-structured interviews with the $2^{\text {nd }}$ year students and alumni who have participated in the Program. The interviews were conducted online in November and December 2019. The article presents which content, teaching methods, learning activities, teacher's role, and students' own strategies matter for the acquirement of knowledge and skills by the students in blended education. It describes how Campus and online phases of the Program matter for students' learning. Next to that, it indicates the challenges related to online study, but also educational methods that may help to overcome them.
\end{abstract}

Keywords: blended education, online study, teaching methods, learning activities, teacher's role, students' learning strategies, learning outcomes

\section{Introduction}

The article presents the outcomes of the research project supported by Linköping University, Sweden. The research project constitutes a part of an umbrella project called Pedagogiska Utvecklingsmedel för E-lärande 2019 (Pedagogical Development Tools for E-learning 2019). The research project focuses on the International Master's Program "Gender Studies - Intersectionality and Change" offered at the Unit of Gender Studies, Department of Thematic Studies, Faculty of Arts and Sciences, Linköping University, Sweden. The program's main focus is on intersectional gender, namely, on gender and its intersections with other axes of differentiation such as sex, sexuality, ethnicity, age, class, and (dis)ability. The program is taught in English and is offered to Swedish and International students as a one-year option, 60 ECTS, or a two-year option, 120 ECTS since 2012. The curriculum is organized in such way that courses run one after another, and each course lasts from four until ten weeks. Importantly, the program relies on blended, face-to-face and online, education. Every academic year there are three one-week meetings (in the fall, winter, and spring) at the Campus combined with online teaching and learning.

The main aims of the research project are to determine which teaching content, teaching methods, learning activities, teacher's role, and students' own strategies matter for learning i.e., for acquiring knowledge and skills/competences (Note 1) in an international blended, face-to-face and online, Master's Program, and to present students' experiences with face-to-face and online education in the Program. The project is based on qualitative, semi-structured interviews with the $2^{\text {nd }}$ year students and alumni who have participated in the Program. The interviews were conducted online in November and December 2019. The students were asked to reflect on teaching content/teaching methods/learning activities/teacher's role/their own strategies, and technology vis-à-vis their acquirement of skills/competences in blended MA Program that they have participated in. Furthermore, they were asked to reflect on how teaching content/teaching methods/learning activities/teacher's role/their own strategies, and technology corresponded with community building in the Program. They were also invited to share their experiences with learning and community 
building online and during face-to-face meetings. Finally, they were asked if being at the beginning, in the middle and at the end of the study mattered for their learning and community building in blended education. The data collected during the interviews was processed and analysed using qualitative analysis method namely thematic content analysis (TCA). "A satisfactory TCA portrays the thematic content of interview transcripts (or other texts) by identifying common themes in the texts provided for analysis. (...) The researcher groups and distils from the texts a list of common themes in order to give expression to the communality of voices across participants" (Anderson, 2007:1). In this article, I will present the results related to the first, third and the fourth question. Yet, the reflection on technology and skills (which constituted a part of the first question) similarly to the reflections on community building (the second question and a part of the third and fourth question) have generated data that requires separate discussion and publication.

The interviewed students determine which teaching content and methods, learning activities, teacher's role, and students' own strategies matter for their acquirement of knowledge and skills. They also indicate that the fact that learning happens either during face-to-face meetings on Campus or in an online context matters significantly for the achievement of knowledge, skills and competences. Notably, according to the students an online phase appears to be more challenging than face-to-face phase. Therefore, they bring forward suggestions for educational methods i.e., teaching methods, learning activities, teacher's role, and students' own strategies that can help to overcome these challenges. Importantly, the interviewed students point out two factors, which in their opinion matter for learning. The first one relates to the fourth question and concerns the importance of time in the learning process. The second one is the students' extra addition and relates to the international, diverse and intergenerational aspect of the Program.

In this article, first, I will outline which content, teaching methods, learning activities, teacher's role, and students' own strategies matter for the acquirement of knowledge and skills by the students. Secondly, I will describe how Campus and online phases of the Program matter for students' learning. Thirdly, I will indicate the challenges related to online study, but also educational methods that may help to overcome them. Fourthly, I will present the previously mentioned two factors that according to the interviewed students matter for learning. The article continues with a summary of the research findings and discussion, and ends with concluding words.

\section{Results. Content, Teaching Methods, Learning Activities, Teacher's Role, and Students' Strategies Vis-à-vis Learning}

With regard to content, the students highly appreciate the fact that the subjects/topics of the assignments, including master's thesis, are open allowing them to freely choose themes to explore, which significantly boosts their level of responsibility and creativity. One of the students says, "It was good to choose the subject of what I was going to write about [because] [i]t helps students to be more independent and start to think and be a bit more creative. (...) As you feel freer, it becomes more interesting." Since content and form are tightly connected, the students also appreciate the teachers' encouragement to apply creative writing styles in their written assignments. One of the interviewed students underlines that, "(...) the opportunity for creative learning and creative responses in essays (...) was brilliant." What also matters for learning is the possibility to bring in and address personal experiences and opinions, and learn from them. The same student says, "We really facilitated each other learning not just of the course materials but of life itself. (...) [The Program] allows people to bring all those messy things of life into the learning that they are doing and I think at that level it is incredibly successful. (...) every bit of that Master's Program made you bring together yourself and life experiences and academic learning in some positive way." Another student mentions, "I expressed more my personal opinion. I put the 'I' in my essays. At the beginning, there was no 'I', always the third person talking. Slowly, slowly, I put myself, I expressed my feelings." The other student emphasizes that, "What made me personally feel involved was always this in a way share your own thoughts, share your own experience. It is not only reflect on what I gave you to read but how does that affect your life (...) or how this can be used in the future, so those kinds of assignments in a way, where I had to involve my own personality or experiences, were those that I found easy for me."

Interestingly, in relation to teaching methods and learning activities the students define interactions, conversations, and discussions as significantly supporting their learning as during face-to-face as during online phase. In the Master's Program "Gender Studies - Intersectionality and Change," reflection diaries, online tutor and co-tutor groups, among other teaching activities, are meant to create a ground for interactions and discussions. Reflection diaries allow students to express in a free style their thoughts, emotions and bring forward life experiences related to a lecture and readings of the week. Sometimes, courses' coordinators change the content of the reflection diary yet, what remains unchanged is the way, in which students express their points of view related to the assigned content. 
Reflection diaries are discussed in the online tutor and co-tutor groups. The tutor groups are led by a teacher whereas the co-tutor groups are formed by the students only. During tutor/co-tutor groups' meetings, students reflect on the issues described in the diaries together. Why are interactions and discussions so important? One of the students suggests that discussions allow reformulating what one has been learning and improve understanding of the complex issues, namely, if something is unclear other students' reflection and feedback helps one to comprehend it. Another student points out that discussions in the tutor/co-tutor groups enable students to exchange ideas, go deeper in the material and by doing so improve the way of thinking. Yet another stresses that discussion enables one to think through what have been presented in a lecture or in assigned readings. The same student also emphasizes that talking to others is also crucial because it allows different perspectives on the same thing to emerge and enables "[s]haring of different abilities with the same text." Overall, reflection diaries and online tutor/co-tutor groups are highly appreciated as a good teaching method/learning activity vis-à-vis the need for interactions and discussions.

Additionally, reflection diaries are also described as a source of inspiration, which is seen as important for learning. The inspiration, as the students point out, comes from reading each other's reflections that embody students' thoughts, feelings and life experiences related to the topics of lectures and assigned readings. Moreover, since reflection diaries allow processing of what has been read or listened to during a lecture; they form a sort of an extra knowledge reservoir that can later be used for doing final assignments.

The interviewed students also stress the import of the role of the teacher. One student emphasizes how important it is if a teacher is "full of life." Another student mentions that teacher should be in control of the teaching situation and should not allow negativity (either in relation to mutual students' comments or in relation to the presented content) to grow. Yet another student stresses how important it is when a teacher allows self-expression concomitantly guiding the discussion,

The feeling that there is a space, safe space for everyone to share their stuff. (...) All teachers did good job in moderating discussions, and trying to give space where space was needed, and trying to give guidance where guidance was needed. (...) Sometimes of course ideas are not thought through, or arguments are rather shitty, but then you learn so I was not afraid to put out half way done ideas because there was always someone might be a co-student or teacher that would probably respond in a way that gave me that spark, a new idea in me.

For the interviewed students it is crucial that a teacher is open-minded, interested in its students, supportive, and attentive to their comments and questions. "I had very good relations with all teachers. They were always open and willing to hear from us, to answer your questions and concerns, and we had a very good collaborations in both years;" "You felt that your teachers were listening to you instead of saying is like this, being very authoritarian. Would listen to you if you had a suggestion;" "To be in an environment that you can work, that you can talk, that you are empowered, that is the part of a learning program." Notably, one of the interviewed students mentions the import of sympathy and appreciation between teacher and student in the learning context what greatly facilitates achievement of knowledge and skills/competences.

If there is a resonance with someone that is teaching then something happens and if not then there is not a lot happening. (...) If I like the person, or what they do, or how they teach, or if I already like the content then it just goes easy, I am more motivated. I easily connect to the content if I like the person that is bringing the content. (...) Or if the teacher gives me the feeling that they actually appreciate that I am there and that they appreciate what I bring to the table. (...) Sympathy. Having a place of mutual learning. Not throwing knowledge at you. (...) This whole thing about resonance I would say only works when the person, who is teaching, is willing to be affected and have affected in the situation.

Finally, the students appreciate when a teacher brings in its own experiences into the learning context. One student says, "You are getting very strong because of the ways those people were facing their life. When you put personalities into a teaching, you are making teaching better."

Importantly, the students stress that their own learning strategies matter for their learning, and define one of these strategies to be a constant effort to enrich one's knowledge on one's own. For example, one of the students says that she always searchers for an additional information concerning discussed topic on the Internet. With regard to learning strategies, they also mention that organization of work is crucial and that it is important to make own schedules and to organize one's time in such ways as to be able to reconcile study (reading, writing, attending teaching/learning activities) with work and private life. The need to enrich one's knowledge and organize one's time are seen as important for online and Campus learning alike. Interestingly, one student emphasizes how important it is to be curious, to want to have a grasp, to have a desire to understand a theory, a concept well enough to be able to 
use it. This curiosity, this desire makes her learning strategy to be about "reading, tearing to pieces until I got it." Other strategies include reading and underlying what is interesting and copying these to a notebook; downloading articles, reading, writing keywords, and engaging with assignments; watching the pre-recorded lectures, writing down what is more important and going through/revisiting taken notes to do the assignments; reading, analysing, reflecting, and making notes.

It is also important to underline that it is never just teaching method or own learning strategy that matters for acquiring knowledge, skills and competences. One student makes this very clear when saying, "They [interactions with students, teachers, readings] were speaking to me. It was like me speaking. It was fascinating. So it is a bit of everything, it is the books, it is the interactions (...) it is not one thing."

The interviewed students also indicate what could be improved. They stress that what they would need would be to expand the teaching methods and learning activities beyond mainly talking/reading/writing. One student suggests to have more "hands on" exercises in both, face-to-face and online learning context. She proposes doing small case studies or have scenarios to work on e.g., focusing on difficult situations, which someone faces, and how to overcome them, how to empower oneself. Another student says that she would welcome "study visits" e.g., visiting organizations or enterprises where (in this particular study context) theories intrinsic to the field of Gender Studies are put into practice. Another student emphasize the need for involving the body and affect more into learning practices, "To really get into contact with what is in a text, or what is in a video, or whatever, I kind need to move it through the body, and I need to allow it to touch me."

\section{Results. Campus and Online Teaching and Learning}

The very fact that study happens on Campus and online matters significantly for the students' learning.

Face-to-face phase allows students to meet in real life. According to the interviewed students, meetings in real life enable one to feel that here are "real people" (teachers and co-students). One student makes this very clear when stressing that, "What make this Program successful for me is also these face-to-face meetings. Because it is this embodiment, you get the aura of the people, but you get this feeling that you are together with this people. (...) It has to do with the material, with the body, with all these stuff, with our aura, our energy. (...) Because people move, because of the bodies." Another student describes the import of meeting in a real life with real people for learning very exquisitely when saying that,

Having met those people in real life, having hugged those people, having shared the bottle of wine with some of them is what made me appreciate the community even more, and for someone who has never been physically there and maybe only participated online I guess it is harder because what made me look forward to all the face to face weeks was meeting the people and also meeting the teachers because I knew that, you know, something magical sometimes happens and there are conversations or discussions that stick with me for many weeks to come and were super inspiring to me.

The content of the quote above shows how meetings in real life may facilitate learning: "conversations or discussions that stick with me (...) and were super inspiring," but also how important it is to spend time with peers in-between lectures and seminars. Those meetings, spending time together, among other things, allow students to bond and those bonds encourage them to continue with their studies. One student says, "Sharing personal lives and what you are going through, and this helps you to continue. Having support, otherwise you could easier dropped out. You could do it! Encouraging each other. Pushing you to become better. Giving you ideas. Team that is cheering you up."

Meeting in real life also makes students to feel that this is a "real study" - "I felt as a part of the university, of the classroom." In real life meetings evoke feelings of knowing, of familiarity and of being there. One student says, "It helps to meet, to take it more seriously. It grounds it a little bit more. I think that some people might see distance studies as less serious, or like easier, or of less importance, or of less weight, and I think that the fact of coming gives us also the feeling that we are there." Taking the study more seriously can be seen as augmenting students' commitment and motivation for learning. Moreover, the meetings at the Campus are described as increasing interactions. The students also emphasize that face-to-face encounters make interactions and discussions to be more fluid and without delays, to get deeper faster, and lectures and seminars to be more dynamic/involving. All these elements are assessed as improving students' learning.

The interviews have shown that online study does not remain indifferent for the students' learning. The students indicate that online learning enables different yet, positive for learning interactions with a lecture e.g., a lecture can be viewed at any time, paused, move backwards, or watched again. Online study also allows one to work at own pace. One student mentions that, "It allowed me to work on my own pace and have some individual learning and 
follow my own strategies. For example, the ways that I approached the academic texts, how many times I want to go through the texts, and highlight the most important parts, and it was good that I had the time to work on my assignments, take my time to read and write (...), good learning process." Another students says that, "Having my own timeframe, of being at home most of the time, online communication, and the freedom to ok I am just not going to read or write anything today but I might read or write twice as much tomorrow, worked for me."

\subsection{Online Challenges and Educational Methods to Overcome Them}

According to the students, an online phase comes with its challenges, namely, it does not happen in real life and by extension does not allow for increased/recurrent interactions what could potentially impair the learning process. Since for the interviewed students interactions/discussions are a key to a positive learning experience, they emphasize the need for frequent interactions including real time interactions with both teachers and co-students in online context. The students stress that online teaching methods and learning activities, which are adopted in the MA Program "Gender Studies - Intersectionality and Change," generally meet the need for frequent and recurrent online interactions/discussions and thus support their learning. The MA Program enables students to meet with their peers during already mentioned online co-tutor groups meetings and online seminars, and with teachers during previously mentioned online tutor group meetings, which occur in the first semester, and again during online seminars. To have the online tutor groups next to the online co-tutor groups at the beginning of the study seems necessary as this helps students to understand how to proceed and organize in online co-tutor groups where they meet with their peers. "I think it was necessary to have a tutor at the beginning. They could coordinate us, keep an eye on the work that was done or on the time as well. But then it was ok not to have a tutor because we knew each other better and we felt comfortable and we simply knew what to do;" "Easier with a tutor. But when you know each other it is ok without the tutor." Importantly, the co-tutor groups also allow students to simply spend time together, bond and get encouraged. They stand for the space that in face-to-face meetings occur in-between lectures, seminars or workshops. The most frequently adopted structure of the online week namely, pre-recorded lecture (at the beginning of the week), co-tutor/tutor group meeting to discuss, mentioned previously, written reflection diaries (in the middle of the week), seminar (at the end of the week) is positively assessed by the interviewed students. "It was very innovative Program and it offered me a lot and in general it had a good structure and there was a balance and there was not too much workload but not too less workload." However, students studying in online context do need to feel that they are able to get in touch with the teachers and peers not only during online meetings. Thus, they stress how important it is to be able to contact teachers, e.g., via email, and to get a relatively quick response to the questions and inquiries posed, and simply feel the support. "If you have support group around you and you have people that you can rely on then you learn more easily. If you know for example that you can contact your teacher at any time and ask for help or if you know that you can ask your fellow students and they can give you feedback and support, it is really important." Furthermore, since students submit their assignments online, they say they would like to receive more feedback and guidance from the teachers on their written exams.

Since, in the online context encounters are technologically mediated and thus, differ from encounters in real life, the students emphasize that it is crucial that pre-recorded lectures are vivid and intense. They also stress that it is important to incorporate power points/lecture's outline to the pre-recorded lecture and/or upload them separately to the existing learning platforms. Furthermore, since online discussions differ from face-to-face discussions (e.g., one person needs to speak at the time; it is more difficult to determine - on the screen full of little boxes with faces in them- who is speaking at the moment; there are delays or problems with sound/vision; bodily clues are missing from the discussion) some students find it hard to be vocal during online meetings. Thus, the interviewed students suggest thinking about pedagogical ways of encouraging the most silent peers to actively participate in the ongoing online discussions. Moreover, since during online study the contact between students and students/teachers may only happen online, it is important not to do last minute changes e.g., not to change the time of online activity or a link to online room - as, as one student mentions, "Regularity helps in online education."

Importantly, even though there are meetings during an online phase, students still mostly have to study on their own. Commitment, determination, personal effort, and self-discipline are recognized as essential elements of one's own learning strategies in the online context. One student mentions that, "It was my decision [to follow this program] then I wanted to participate, which I think because of the type of the Program nobody forces you to follow this type of the Program." Yet another student emphasizes that, "Being there was the choice for me."

However, students' determination has to be matched with teachers' commitment and support. One student mentions,

One's own learning habits and discipline is super important to finish the distance course or Program within the timeframe. It needs a lot of discipline. You need to be active and you need to be working on 
whatever is going on. Maybe not every day but certainly every week and missing out the whole week really sets one back. And I guess this requires a whole lot determination from the student to keep up with the Program because it is so easy if you do not have to go, you know, to any physical classroom and you do not necessarily have someone checking your attendance here and there and checking your homework or whatever. Then it is really on you, on the student to complete the Program. And I guess that is just a question of interest and motivation. (...) When one is interested (...) and wanting to learn, and wanting to keep up then what I felt was a whole lot of the support from the staff and the possibility to have questions answered even outside of the classroom schedule. (...) So it is the determination I guess. (...) If one is less determined, less active, more in a way passive and not reaching out, not actively engaging then I could imagine that they would maybe feel left alone. (...) If one is determined, has a plan and knows what they are doing this for, I think it is amazing, it is flexible, and distance or online study is such a huge advantage.

And teachers', but also other peers' commitment and support.

I am a person who does not give up so I would never quit. Even if I did not like it and I did not have motive I would just finish because I started it because it was my choice to start it. But then again it was also the support from the teachers and the fellow students and the fact that I met the right people.

The interviewed students highlight the import of other peers' commitment for creating a positive online learning environment, which by extension facilitates learning i.e., achievement of knowledge and skills. They stress that everybody should be actively engaged in their study; they should read, watch the pre-recorded lectures, be responsive, write reflection diaries, be present at the online teaching/learning activities, contribute actively to the discussions, and do not choose noisy locations when connecting to online meetings. Finally, it is also important that during online meetings co-students welcome mutual self-expression even if they disagree with each other. One student mentions, "If you find it difficult to participate in a group, or if you feel that the group is hostile, or you are not allowed to talk or are criticized then the learning process is not as good as you are expecting." Another student underlines, "We should allow spaces to disagree. (...) If there is something that does not really fit all together that is also when you need to start thinking differently on how you can agree maybe on something in between about your both ideas."

\section{Results. Two Factors}

Importantly, the interviewed students point out two factors, which they define as essential for knowledge/skills/competences' achievement.

They underline the importance of time in the learning process. One stresses, "With time I learn how to work faster. How to integrate a lot of information. How to read more efficiently and where to put my focus on and I learn how to learn from others as well." Another one emphasizes, "Getting knowledge takes time. Until it becomes a real knowledge. Different courses enrich us - but it takes time. At the beginning, it is difficult. (...) Big difference. First year, new, compact, learning lots of things. Now [at the second year], it is getting better. I can manage. It does not get easier but it gets more comprehensive and manageable. Improving analysis. Knowledge and skills getting better. Texts more comprehensive." Yet another one says, "Important knowledge is learned over time, come and come back again. (...) Beginning: some concepts strange and then little by little it comes again and you understand better and it finds its place in you."

They also mention the significance of international, diverse and intergenerational aspect of the Master's Program for their learning. Here are some of the students' statements: "Great to have a very different type of people. Older and younger, Swedish with foreigners. (...) I learned some stuff from the young people;" "A lot learned from the fellow students - exchanging ideas, suggestions and experiences. (...) Social skills as coming in contact with people from different countries and cultures: exchanging views and perceptions;" "I learned so much just from the diverse cultures and backgrounds that were represented in those classrooms, which I think the Program would not in the same way have been able to teach me if it was a strictly local, non-online course. So I liked that a lot;" "People and backgrounds, identities, diversity you can learn so much just by being, moving around in this Program. (...) So many perspectives are always brought up which means that you challenge your way of thinking and to me knowledge wise (...) I cannot think of a better way of expanding my own ideas about what I even do not know and how I can even make sense of it."

\section{Summary of the Research Findings and Discussion}

The interviewed students determine which teaching content and methods, learning activities, teacher's role, and 
students' own strategies matter for their learning in the blended, face-to-face and online, Master's Program. They also describe how Campus and online phase matters for their achievement of knowledge and skills/competences. Furthermore, they indicate the challenges the online phase may bring about and suggest educational methods to overcome them. Finally, they define two important factors as crucial for their learning.

Some of the determined teaching methods, learning activities, content, roles of a teacher, and students' strategies are deemed important for both face-to-face and online phase of the Program. With regard to content, what according to students facilitates learning (e.g., achievement of skills/competences such as creativity, responsibility and independence) is the content, e.g., a content of assignments, which is open and can be freely decided upon by the students. What is also seen as important is the possibility to apply creative writing techniques and to bring forward personal experiences and opinions (e.g., Just, 2011; Koobak, 2014; Koobak \& Thapar-Björkert, 2014; Lykke, 2017; Lykke, 2014; Lykke, 2014 a). Creative writing techniques combined with personal experiences may allow students "to develop skills in critical social fantasy (...) [which] can enable students to imagine alternative futures and translate them into transformatory professional work" (Lykke, 2017:191). As for teaching methods and learning activities, what the students welcome the most are methods and activities such as e.g., reflection diaries, tutor and co-tutor groups' meetings, which facilitate interactions, conversations and discussions and by extension understanding, critical and creative thinking (e.g., Ying, 2020; Croft, Dalton, \& Grant, 2010). It is also important that methods and activities are a source of inspiration such as e.g., reflection diaries are. What inspires students are their mutually shared thoughts, feelings and experiences related to lectures and readings. Inspiration appears to be crucial in learning as inspiration may increase motivation, confidence and creativity (Thrash \& Elliot, 2003). It also matters that in a given course, there is a learning activity that next to a lecture/seminar facilitates formation of an extra knowledge reservoir that can be used for upcoming final assignments, and again reflection diaries are accessed as an activity that significantly contributes to this. The students would also welcome "hands on" exercises such as work on small case studies (to empower oneself), "study visits" (to know how to apply a theory in the practice) and integrating body (e.g., Lawrence, 2012; McDonough, Forgasz, Berry, \& Taylor, 2016) and affect (e.g., Hickey-Moody, 2009; Juelskjær, 2017; Just, 2016; Koobak, 2014) more into learning context. As argued by McDonough et al., (2016) there is an urgent need to identify "how to flatten both our own [lecturers], and the institutional, hierarchical privileging of discursive-cognitive-logical-rational knowledges over embodied-felt-emotional ones" (2016:438). Concerning teacher's role it is crucial that a teacher is "full of life," open minded, supportive and attentive, stimulates positive atmosphere in a classroom, allows for students' self-expression, shows sympathy and appreciation, and brings in its own experiences to the learning context (e.g., hooks, 1994). These supports students in acquiring knowledge, but also boost their motivation, confidence and creativity. With regard to students' own strategies, what matter the most for achievement of knowledge and skills/competences are efforts to enrich one's knowledge on one's own and to organize well one's time, but also simply reading, watching lectures and taking and revisiting notes. Even though the latter one i.e., "repetitive reading" is not considered to be the best learning method (Callender \& McDaniel, 2009), the interviewed students still recognize it as an important learning strategy. Furthermore, curiosity and own activities that can satisfy it (such as "tearing to pieces" a complex theory/concept in order to comprehend it) are also seen as an important strategy. This resonates well with the neuroscientist Dean Burnett's (2016) reflection on curiosity. He states that people are "inherently curious," "drawn to novelty value" and "are inclined to explore something novel if there is an opportunity to do so" (2016:98).

The interviewed students emphasize that Campus and online study matter for their achievement of knowledge and skills/competences differently. Meetings in real life enable meeting "real people" what enables meaningful and inspiring conversations, creates feelings of being together and fosters bonds between people that function, among others, as a form of encouragement. According to the students, all these elements facilitate learning. Christie L McDaniel (2008) in a chapter "Removing Space and Time: Tips for Managing the Virtual Workplace" when writing about virtual teams underlines that, "all teams should meet face-to-face at least once, in order to develop social bonds with one another" (2008:20). Referring to the research by Zaccaro and Bader (2003), McDaniel writes that according to them "it is difficult for virtual team members to build high levels of trust and identification with the team because these emotional states are typically developed in person" (2008:20). Furthermore, meetings in real life allow students to feel that their studies are "real," that they are "a part of university." The feelings of being there, of familiarity allow students to approach the study as "serious" what can be seen as facilitating learning by increasing commitment and motivation. Moreover, real life meetings increase interactions, which according to the students are crucial for positive learning experience, and make interactions/discussions to be fluid and deeper in contrast to online conversations. Furthermore, the Campus-based lectures and seminars are assessed as more dynamic/involving what again, according to the interviewed students, facilitates learning. Ragusa (2017) in her article on 
"Technologically-mediated communication: student expectations and experiences in a FOMO society," discusses results of the students' survey on distance education (DE) at Australian University. One of the findings points out to the fact that, "Regardless of the convenience (...) electronic communication permitted, DE [distance education] students simply failed to believe interactive online platforms were a suitable substitute for 'real' human interactions. Face-to-face interactions, unlike TMC [technologically-mediated communication], were perceived motivational and thus crucial for academic learning" (Ragusa, 2017). With regard to online phase, the students appreciate the fact that they can work at their own pace (e.g., Ragusa, 2017). They also appreciate the interactions with pre-recorded lectures -the possibilities to pause, to reflect, to watch again (e.g., Hadgu, Hoang-Vy Huynh, \& Gopalan, 2016). This could be because, "The ability to pause and replay the videos may aid in memorization of new information whereas in LL [live-lecture], students rely on their ability to take adequate notes" (Hadgu, Hoang-Vy Huynh, \& Gopalan, 2016:110).

An online phase of the study is described as more challenging than face-to-face study. According to the students, this is because it does not allow increased/recurrent interactions/discussions to occur. Due to this, it is crucial that in the online learning students have possibilities for frequent real time interactions/discussions with teachers and co-students alike (e.g., Frisby, Limperos, Record, Downs, \& Kercsmar, 2013; Croft, Dalton, \& Grant, 2010; Lowenthal \& Parscal, 2008) during e.g., online co-tutor and tutor groups and seminars. Frequent real time online interactions/discussions with co-students also allow spending time together, bonding and getting encouraged. There is also a need for interactions with peers and teachers outside the scheduled online meetings. Getting teacher's prompt response to an email or extensive feedback and guidance concerning assignments are deemed essential (e.g., Lowenthal \& Parscal, 2008). The possibility to be/feel in touch with co-students and teachers is crucial for feeling supported, and that support is vital for students' learning (e.g., Chiu, Tzung-Jin, \& Lonka, 2021; Croft, Dalton, \& Grant, 2010). Croft, Dalton and Grant (2010) referring to Gammie, Gammie and Duncan (2002) stress that, "If appropriate support is not provided for students, students withdrawal from the course may be more likely" (2010:33). Furthermore, since an online phase brings about technologically mediated encounters, the students emphasize that it is vital to encourage less vocal students to participate in online discussions. Concerning online participation i.e., "taking part and joining in a dialogue for engaged and active learning" (2005:214), Vonderwell and Zachariah (2005) claim "that online learner participation and patterns of participation are influenced by the following factors: technology and interface characteristics, content-area experience, student roles and tasks, and information overload" and as such they stress that "careful construction of online roles and tasks, and insights into how groups and learning communities develop becomes crucial" (2005:225). They also argue that, "Research that investigates issues of interface design, learner participation patterns, and cognitive load in online learning can enable instructional designers and educators to design effective online learning" (2005:225). To continue, the students also stress that it is crucial that pre-recorded lectures are vivid and intense. Hadgu, Hoang-Vy Huynh and Gopalan (2016) in their article on pre-recorded lectures refer to observations by Lovell and Plantegenest (2006) who suggest that pre-recorded lectures might be less effective due to "the lack of visual stimulation and kinesics" (2016:110). Importantly, students point out that their own learning strategy, which is about commitment, determination and personal effort, is essential for positive learning experience during online study. Yet, this determination and personal effort should be matched with teachers' and peers' commitment and support, but also with peers' friendliness and openness to self-expression and difference in opinions. With regard to the latter, Elizabeth Creamer (2004) in her article "Collaborators' Attitudes about Differences of Opinion" refers to Palmer Parker (1988), who claimed "that the exchange of differing perspectives is most likely to contribute to knowledge and learning when it occurs within the context of community where there is a commitment to a common goal and a sense of affiliation among its members" (2004:556).

Finally, the interviewed students determine two other factors, which they define as essential for knowledge/skills/competences' achievement. The first factor is the import of time in learning process. After listening to the students, it appears that the longer one studies the better the learning results are. Yet, what also could be concluded is that the courses in the curriculum should somehow stimulate retrieval of what have been taught already concomitantly expanding forms of learning activities and expanding/adding new information to the material once taught. This partially resonates with the retrieval-based learning that is an approach to learning "which recognizes the central role of retrieval processes in learning and aims to develop new learning strategies based on retrieval practice" (Karpicke, 2016). The second factor is the international, diverse and intergenerational aspect of the learning environment (e.g., Acquah \& Commins, 2016; Mannion, 2016; Just, 2012). Acquah and Commins (2016) argue in the same vein, as the interviewed students do, when stating that, "Learning in such a classroom context ["composed of students from diverse backgrounds"] creates dynamics and tensions that can be explored constructively to bring about more learning, more awareness, and greater opportunities for cultural development" (2016:194). 


\section{Concluding Words}

To end this article, I want to stress that it is appealing to observe that some of the teaching methods, learning activities, content, roles of a teacher, and students' strategies matter/are important as for face-to-face as for online education. Yet, online education seems to be more challenging with regard to the acquirement of knowledge and skills/competences, and as such carefully designed educational methods need to be implemented. Finally, it appears that blended education might be really successful with regard to students' achievement of knowledge/skills/competences. This is because these distinct forms of education, online and face-to-face when brought together in blended teaching and learning, seem to complement each other vis-à-vis students' acquirement of knowledge and skills/competences.

\section{References}

Acquach, E. O., \& Commins, N. L. (2016). International Students' Perspectives of a Diverse Class on Multiculturalism. Journal of Further and Higher Education, 42(2), 193-204. https://doi.org/10.1080/0309877X.2016.1224328

Anderson, R. (2007). Thematic Content Analysis: Descriptive Presentation of Qualitative Data. 1-4. http://rosemarieanderson.com/wp-content/uploads/2014/08/ThematicContentAnalysis.pdf (last accessed 6 August 2021).

Burnett, D. (2016). Idiot Brain. What Your Head Is Really Up To? New York: W. W. Norton \& Company.

Callender, A. A., \& McDaniel, M. A. (2009). The limited benefits of rereading educational texts. Contemporary Educational Psychology, 34(1), 30-41. https://doi.org/10.1016/j.cedpsych.2008.07.001

Chiu, T. K. F., Tzung-Jin, L., \& Lonka, K. (2021). Motivating Online Learning: The Challenges of COVID-19 and Beyond. The Asia-Pacific Education Researcher, 30, 187-190. https://doi.org/10.1007/s40299-021-00566-w

Creamer, E. G. (2004). Collaborators' Attitudes about Differences of Opinion. The Journal of Higher Education, 75(5), 556-571. https://doi.org/10.1353/jhe.2004.0028

Croft, N., Dalton, A., \& Grant, M. (2010). Overcoming Isolation in Distance Learning: Building a Learning Community through Time and Space. Journal for Education in the Built Environment, 5(1), 27-64. https://doi.org/10.11120/jebe.2010.05010027

Frisby, B. N., Limperos, A. M., Record, R. A., Downs, E., \& Kercsmar, S. E. (2013). Students' Perceptions of Social Presence: Rhetorical and Relational Goals across Three Mediated Instructional Designs. MERLOT Journal of Online Learning and Teaching, 9, 468-480.

Gammie, E., Gammie, B., \& Duncan, F. (2002). Operating a distance learning module within an undergraduate work placement: Some reflections. Education and Training, 44(1), 11-22. https://doi.org/10.1108/00400910210416200

Hadgu, R. M., Hoang-Vy Huynh, S., \& Gopalan, Ch. (2016). The Use of Pre-recorded Lectures on Student Performance in Physiology. Journal of Curriculum and Teaching, 5(1), 105-112. https://doi.org/10.5430/jct.v5n1p105

Hickey-Moody, A. (2009). Little War Machines: Posthuman Pedagogy and Its Media. Journal of Literary \& Cultural Disability Studies, 3, 273-280. https://doi.org/10.1353/jlc.0.0024

Hooks, B. (1994). Teaching to Transgress. Education as the Practice of Freedom. London: Routledge.

Juelskjær, M. (2017). Atmospheric Encounters: Generic Competences in Light of Post-humanist Teaching Practices with/on Affectivity. In E. Just \& W. Grahn (Eds.), Theories of Affect and Concepts in Generic Skills Education. Adventurous Encounters (pp. 65-89). Newcastle upon Tyne: Cambridge Scholars Publishing.

Just, E. (2016). Daring to Dare-Theoretical Experiment for Pedagogical Practices and BodyBrain-Embedded Subject. Creative Education, 7, 293-301. https://doi.org/10.4236/ce.2016.72028

Just, E. (2012). Teaching Gender in Interdisciplinary and Transnational Classrooms. In M. M. Wojtaszek and E. Just (Eds.), Quilting Stories (pp. 167-179). Lodz: Wydawnictwo Uniwersytetu Lodzkiego.

Just, E. (2011). If writing has to do with desire, what "kind" of desire is that? Between Jacques Lacan and Gilles Deleuze. In: R. Buikema, R. Griffin, \& N. Lykke (Eds.), Handbook for Postgraduate Research in Women/Gender/Feminist Studies (pp. 261-272). New York, London: Routledge Taylor and Francis Group. 
Karpicke, J. D. (2016). A powerful way to improve learning and memory Practicing retrieval enhances long-term, meaningful learning. American Association. https://www.apa.org/science/about/psa/2016/06/learning-memory (last accessed 14 June 2021).

Koobak, R. (2014). Six Impossible Things Before Breakfast: How I Came Across My Research Topic and What Happened Next. In N. Lykke (Ed.), Writing Academic Texts Differently. Intersectional Feminist Methdologies and the Playful Art of Writing (pp. 95-110). New York: Routeldge.

Koobak, R., \& Thapar-Björkert, S. (2014). Writing the Place from Which One Speaks. In N. Lykke (Ed.), Writing Academic Texts Differently. Intersectional Feminist Methdologies and the Playful Art of Writing (pp. 47-61). New York: Routeldge.

Lovell, K., \& Plantegenest, G. (2006). Student utilization of digital versions of classroom lectures. Journal of International Association of Medical Science Education, 19, 20-25.

Lawrence, R. L. (2012). Coming full circle: Reclaiming the body. New Directions for Adult and Continuing Education, 134, 71-78. https://doi.org/10.1002/ace.20019

Lowenthal, P. R., \& Parscal, T. (2008). Teaching Presence Online Facilitates Meaningful Learning. The Learning Curve, 3, 1-11.

Lykke, N. (2017). Imagining Professional Futures in Feminist Classrooms. In E. Just \& W. Grahn (Eds.), Theories of Affect and Concepts in Generic Skills Education. Adventurous Encounters (pp. 191-211). Newcastle upon Tyne: Cambridge Scholars Publishing.

Lykke, N. (Ed.). (2014). Writing Academic Texts Differently. Intersectional Feminist Methdologies and the Playful Art of Writing. New York: Routeldge. https://doi.org/10.4324/9781315818566

Lykke, N. (2014 a). Passionate Disidentifications as an Intersectional Writing Strategy. In N. Lykke (Ed.), Writing Academic Texts Differently. Intersectional Feminist Methdologies and the Playful Art of Writing (pp. 30-46). New York: Routeldge.

Mannion, G. (2016). Intergenerational Education and Learning: We Are in a New Place. In S. Punch, R. Vanderbeck, $\&$ T. Skelton (Eds.), Families, Intergenerationality, and Peer Group Relations (pp. 1-21). Springer.

McDaniel, Ch. L. (2008). Removing Space and Time: Tips for Managing the Virtual Workplace. In P. Zemliansky \& K. St. Amant (Eds.), Handbook of Research on Virtual Workplaces and the New Nature of Business Practice (pp. 14-23). New York: Information Science Reference.

McDonough, S., Forgasz, R., Berry, A., \& Taylor, M. (2016). All Brain and Still No Body: Moving towards a Pedagogy of Embodiment in Teacher Education. In D. Garbett \& A. Ovens (Eds.), Enacting Self-Study as a Methodology for Professional Inquiry (pp. 433-440). Herstmonceux, UK: S-STEP.

Parker, P. J. (1988). Community, conflict, and ways of knowing. Change: The Magazine of Higher Learning, 19(5), 20-25.

Ragusa, A. T. (2017). Technologically-mediated communication: student expectations and experiences in a FOMO society. International Journal of Educational Technology in Higher Education, 14(39), https://doi.org/10.1186/s41239-017-0077-7

Thrash, T. M., \& Elliot, A. J. (2003). Inspiration as a Psychological Construct. Journal of Personality and Social Psychology, 84(4), 871-889. https://doi.org/10.1037/0022-3514.84.4.871

Vonderwell, S., \& Zachariah, S. (2005). Factors that Influence Participation in Online Learning. Journal of Research on Technology in Education, 38(2), 213-230. https://doi.org/10.1080/15391523.2005.10782457

Ying, J. (2020). The Importance of the Discussion Method in the Undergraduate Business Classroom. Humanistic Management Journal, 5, 251-278. https://doi.org/10.1007/s41463-020-00099-2

Zaccaro, S., \& Bader, P. (2003). E-leadership and the challenges of leading E-teams: Minimizing the bad and maximizing the good. Organizational https://doi.org/10.1016/S0090-2616(02)00129-8 


\section{Note}

Note 1. In this project knowledge and skills/competences refer to the learning outcomes defined for each course in the International MA Program "Gender Studies - Intersectionality and Change" and can be found in the respective syllabi: https://liu.se/studieinfo/en/program/f7mgr/5055

\section{Copyrights}

Copyright for this article is retained by the author(s), with first publication rights granted to the journal.

This is an open-access article distributed under the terms and conditions of the Creative Commons Attribution license (http://creativecommons.org/licenses/by/4.0/). 